\title{
Failure Analysis of Additively Manufactured Polyester Test Specimens Exposed to Various Liquid Media
}

\author{
Israel A. Carrete - Diego Bermudez - Clarissa Aguirre - Fabian A. Alvarez-Primo • \\ Shweta Anil-Kumar • Paulina Chinolla • Michelle Gamboa • Sergio A. Gonzalez • \\ Hugo E. Heredia • Austin M. Hernandez • Emmanuel Levario · John R. Lindquist • \\ Victoria C. Luna $\cdot$ Luis M. Martinez • Victor E. Mendez - Jonathan J. Slager • \\ Leticia Ugarte-Sanchez $\cdot$ Yamile A. Urquidi • Abraham Zamora • David A. Roberson
}

Submitted: 4 January 2019/Published online: 4 February 2019

(C) ASM International 2019

\begin{abstract}
Additive manufacturing platforms that rely on thermoplastic feedstock materials are now expected to fabricate components intended for deployment in a wide variety of environments, necessitating an understanding of the ability of a material to perform within a broad range of conditions. The work presented here explored the effect of submerging two polyester materials widely used in fused filament fabrication processes in five common liquid media: distilled water, apple cider vinegar, Mexican Cocacola, 200 proof ethanol and distilled white vinegar for a seven day duration. Mechanical testing, dynamic mechanical analysis and characterization of the fracture surfaces via scanning electron microscopy were used to understand the effect of liquid media exposure. The effects of polymer degradation due to hygroscopic and hydrolytic mechanisms
\end{abstract}

I. A. Carrete · D. Bermudez · D. A. Roberson $(\bowtie)$ Polymer Extrusion Lab, The University of Texas at El Paso, 500 W University Ave., El Paso, TX 79968, USA

e-mail: droberson@utep.edu

I. A. Carrete $\cdot$ D. Bermudez $\cdot$ C. Aguirre

F. A. Alvarez-Primo - S. Anil-Kumar · P. Chinolla .

M. Gamboa - S. A. Gonzalez · H. E. Heredia .

A. M. Hernandez $\cdot$ E. Levario - J. R. Lindquist .

V. C. Luna · V. E. Mendez · L. Ugarte-Sanchez .

Y. A. Urquidi · A. Zamora · D. A. Roberson

Department of Metallurgical, Materials and Biomedical Engineering, The University of Texas at El Paso, $500 \mathrm{~W}$.

University Ave., El Paso, TX 79968, USA

\section{M. Martinez}

Department of Physics, The University of Texas at El Paso, 500 W. University Ave., El Paso, TX 79968, USA

\section{J. J. Slager}

Department of Mechanical Engineering, The University of Texas at El Paso, 500 W. University Ave., El Paso, TX 79968, USA effects were documented. The need for specific procedures for the testing of the environmental effects on the degradation of additively manufactured polymeric components is also highlighted.

Keywords Electron fractography · Failure analysis . Plastics - Scanning electron microscopy ·

Polymer degradation - Fused filament fabrication .

Additive manufacturing

\section{Introduction}

Widespread proliferation of fused filament fabrication (FFF) additive manufacturing (AM) platforms has led to an increase in the variety of feedstock materials available for end users. Acrylonitrile butadiene styrene (ABS) was once seemingly the material of choice for FFF desktop systems, but concern over the emission of volatile organic compounds (VOCs) and microparticles $[1,2]$ has led to a decrease in the use of this thermoplastic. The emission of potentially toxic media from desktop-grade 3D printers is of great concern, particularly for users in K-12 educational as well as home use environments where adequate ventilation or filtration equipment may not be readily available. Polylactic acid (PLA) has largely supplanted ABS as the "go-to" material for desktop-grade printers to the point where several FFF manufacturers indicate their systems are intended specifically for PLA. Additionally, PLA is currently the most commonly used feedstock for desktopgrade FFF systems [3].

Glycol-modified polyethylene terephthalate (PETG) is another widely used feedstock material for FFF platforms. Like PLA, PETG is a polyester; however, the presence of a 
benzene ring in the terephthalate group (Fig. 1a) leads to an increase in strength and glass transition temperature $\left(\mathrm{T}_{\mathrm{g}}\right)$, making this material suitable for a wider range of applications than PLA. On the other hand, PLA has an aliphatic structure (Fig. 1b) where the physical properties can be controlled by molecular weight (polymer chain length) leading to the ability to tune properties such as $T_{\mathrm{g}}$, ultimate tensile strength (UTS) among others. Furthermore, the addition glycol to polyethylene terephthalate (PET) renders the material unable to crystallize [4], whereas high molecular weight variants of PLA can be either be thermally annealed or strained to induce crystallinity [5-8]. Another attractive aspect of PLA is that it is a biopolymer derived from renewable sugar sources such as corn (in the USA) sugarcane and sugar beet (predominantly in Asia) and parts fabricated from PLA can be composted [7, 9, 10]. The "green" aspect of PLA is of importance considering the attention given to the effect of polymeric waste on the earth's oceans as well as other environmental concerns [11-15].

While mankind's use of polymers dates back as early as the 1600 B.C. when the ancient Mesoamericans used sap from the Castilla elastic rubber tree to make rubber balls [16], the use of polymeric materials in AM applications is relatively recent. Nuances unique to AM fabrication, particularly the effect of print raster pattern on mechanical properties, have been well investigated for fused deposition modeling (FDM) and related FFF variants [17-24], but other aspects related to additively manufactured components and their interaction with the environment have been less explored in the literature. As AM continues to transform from a method of rapid prototyping to a method of end-product manufacturing, the understanding of the effect of the 3D printing process on a fabricated component's susceptibility to environmental damage becomes paramount. Work performed by Kim et al. [25] has shown that print raster pattern plays a role in the amount of moisture absorbed by FFF-manufactured components made from $\mathrm{ABS}$ and that this absorption will decrease the mechanical strength of printed parts as compared to injection molded control specimens.

The work presented here explores the effect of exposure to common liquid media of additively manufactured test coupons composed of PLA and PETG. Tensile test specimens exposed to five individual liquids-apple cider vinegar (CV), distilled white vinegar (WV), 200 proof ethanol (ETOH), distilled water (DW) and Mexican Cocacola (Coke)-were compared to unexposed control specimens. The fracture surfaces of representative specimens were analyzed via scanning electron microscopy (SEM). Finally, dynamic mechanical analysis (DMA) was carried out on specimens exposed to the same liquid media to explore the effect of this media on storage modulus, $\mathrm{T}_{\mathrm{g}}$ and maximum loss tangent $(\tan \delta)$.

\section{Experimental Procedure}

Two polyester feedstock materials: (1) PLA (Proto-Pasta HTPLA, Protoplant, Vancouver, WA, USA); and (2) PETG (Inland, MicroCenter, Hillard, OH, USA) were purchased in the form of a $1.75 \mathrm{~mm}$ filament from Amazon.com. Tensile test specimens were fabricated using a Prusa i3 (Prusa Research s.r.o, Praha, Czech Republic) following the dimensions of the type 5A geometry of the ISO 527 tensile test standard [26]. All specimens were printed with a $0.25 \mathrm{~mm}$ layer height, an alternating $45^{\circ}$ raster pattern with a $100 \%$ infill and the print head was outfitted with a nozzle possessing a $0.4 \mathrm{~mm}$ diameter orifice. The printer parameters in g-code format were generated by opensource Slic3r software. Machine parameters for each material are seen in Table 1 and representative tensile test specimens along with a schematic depicting the raster pattern are seen in Fig. 2. In order to promote bed
Fig. 1 The chemical structures of (a) PETG and (b) PLA
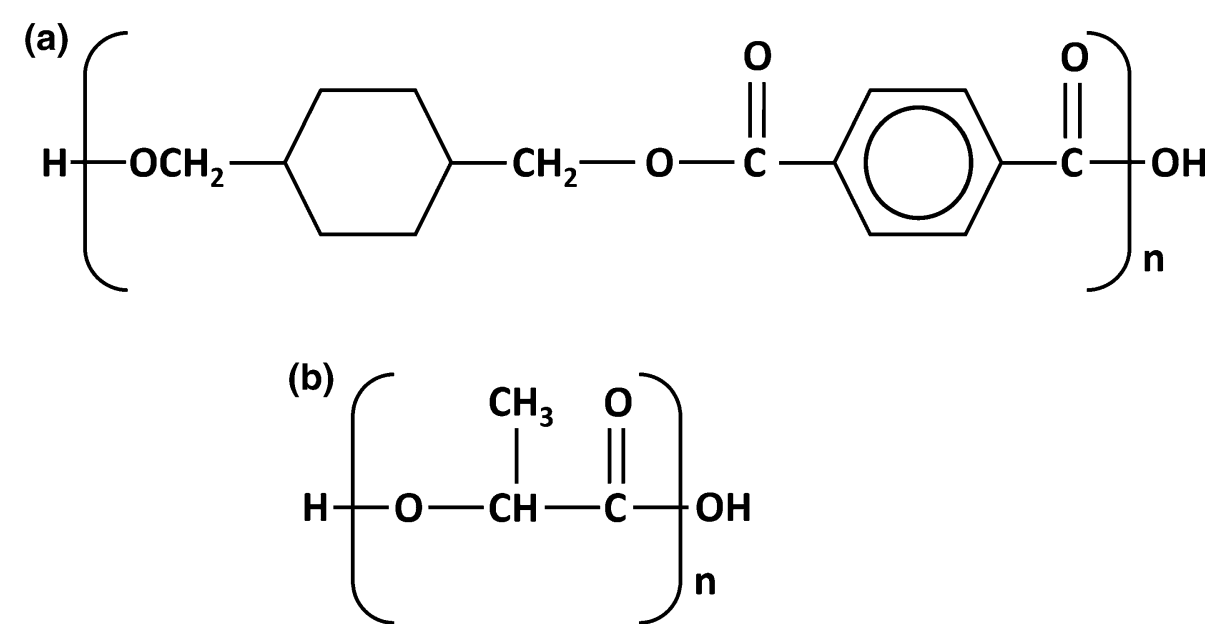
Table 1 Machine parameters for the two materials evaluated in this study

\begin{tabular}{lrr}
\hline Parameter & PETG & PLA \\
\hline Bed temperature $\left({ }^{\circ} \mathrm{C}\right)$ & 240 & 210 \\
Nozzle temperature $\left({ }^{\circ} \mathrm{C}\right)$ & 90 & 50 \\
Perimeter print speed $\mathrm{mm} / \mathrm{s}$ & 30 & 30 \\
Infill speed $\mathrm{mm} / \mathrm{s}$ & 80 & 80 \\
\hline
\end{tabular}

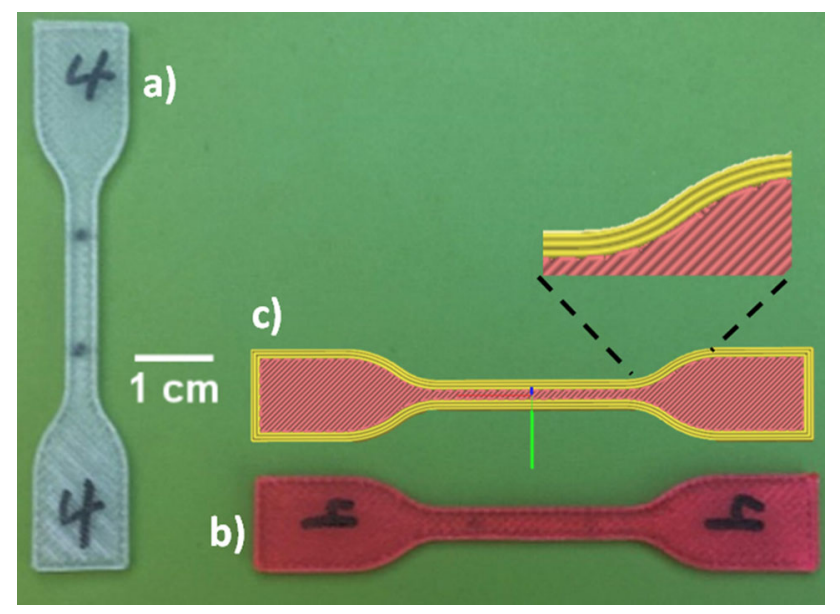

Fig. 2 Printed specimens composed of (a) PLA, (b) PETG. (c) Schematic of the raster pattern that alternates at $45^{\circ}$

adhesion, Scotch Brand blue painters tape (3M, Maplewood, MN, USA) was affixed to the heated print bed. The $45^{\circ}$ crisscross raster pattern was chosen because Kim et al. [25] demonstrated this pattern to be the least susceptible to moisture absorption, and we wished to perform this experiment as a best-case scenario for additively manufactured components.

Tensile testing was performed through the use of a MTS (MTS Systems Corporation, Eden Prairie, MN, USA) High Elongation Machine (Model AHX800) with a Criterion C44104 load cell and an integrated extensometer (Model 634.25F-24). While performing tensile testing, three problems were encountered: (1) slippage of some of the specimens within the testing grips; (2) failure of the tensile test specimen outside of the gate area within the extensometer (Fig. 3); and (3) bending of the tensile test specimen during the insertion into the grips (Fig. 4). These problems were consistent across each of the sample pools lending confidence to yield strength (YS) values; however, we do not report \% elongation in this study. The mechanical testing did produce fracture surfaces that could be further analyzed. Furthermore, specimens that did not yield usable results were removed from the dataset. More details pertaining to failure outside of the gage section will be discussed below.

Dynamic mechanical analysis (DMA) was performed using a PerkinElmer Model DMA 8000 (PerkinElmer

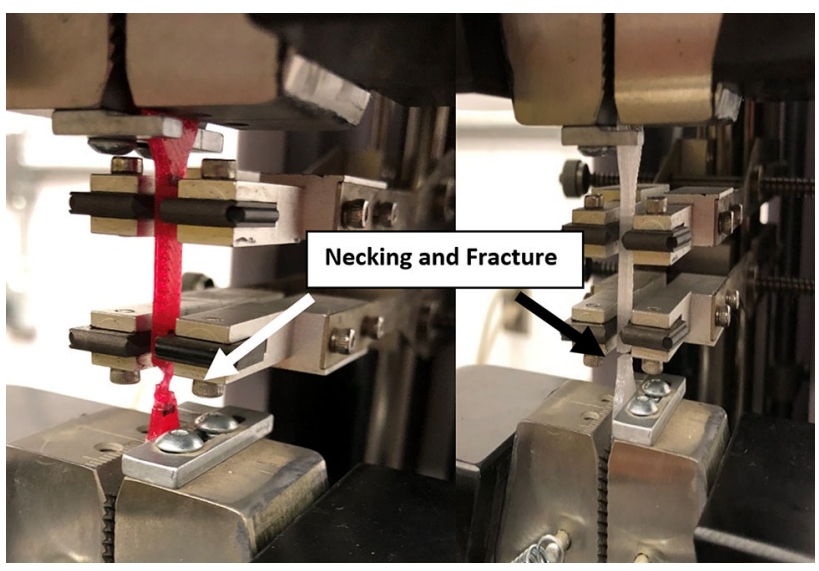

Fig. 3 Examples of specimen failure outside of the extensometer

Waltham, MA, USA). All specimens had a length of $50 \mathrm{~mm}$, a width of $9 \mathrm{~mm}$, and thickness of $3.5 \mathrm{~mm}$. The specimens were tested in dual cantilever mode at a frequency of $1 \mathrm{~Hz}$ and dynamic force of $2 \mathrm{~N}$. A temperature scan was carried out for all tests. For PLA, the scan ranged from $45^{\circ} \mathrm{C}$ to $80{ }^{\circ} \mathrm{C}$ at a rate of $7{ }^{\circ} \mathrm{C} / \mathrm{min}$, while PETG had a range from $60{ }^{\circ} \mathrm{C}$ to $110^{\circ} \mathrm{C}$ at a rate of $10^{\circ} \mathrm{C} / \mathrm{min}$. The ranges for each sample were arbitrarily chosen to clearly exhibit a transition within the given range. Analysis of the data was performed through the use of PerkinElmer Pyris ${ }^{\mathrm{TM}}$ software.

Scanning electron microscopy (SEM) was utilized to perform fractography on representative tensile test specimens from each sample pool. The instrument used was a Hitachi SU3500 SEM (Hitachi High Technologies America, Irving, TX, USA). In order to reduce the effect of electron charging, the microscope was operated in variable pressure mode at $60 \mathrm{~Pa}$. An accelerating voltage of $10 \mathrm{kV}$ was used, and images were obtained using a backscatter electron (BSE) detector.

After the tensile test coupons were fabricated, sample pools of four specimens each were separated into baseline and exposed groups. The exposed specimens were submerged in each given liquid for a duration of seven days at room temperature in a Pyrex beaker, which was sealed with Parafilm after the specimens were inserted. After the seven day exposure, the specimens were removed from the beakers, blotted dry with a paper towel and then sealed in Ziploc bags so that they could be tested in a near-wet state. Samples for DMA testing were processed in the same manner as the tensile test coupons; however, there was only one specimen per liquid type.

\section{Results and Discussion}

Representative stress strain curves from each of the sample pools are displayed in Fig. 5, while results of YS are tabulated in Table 2. A Tukey-Kramer Honest Significant 
Fig. 4 Examples of specimen bending within the test fixture
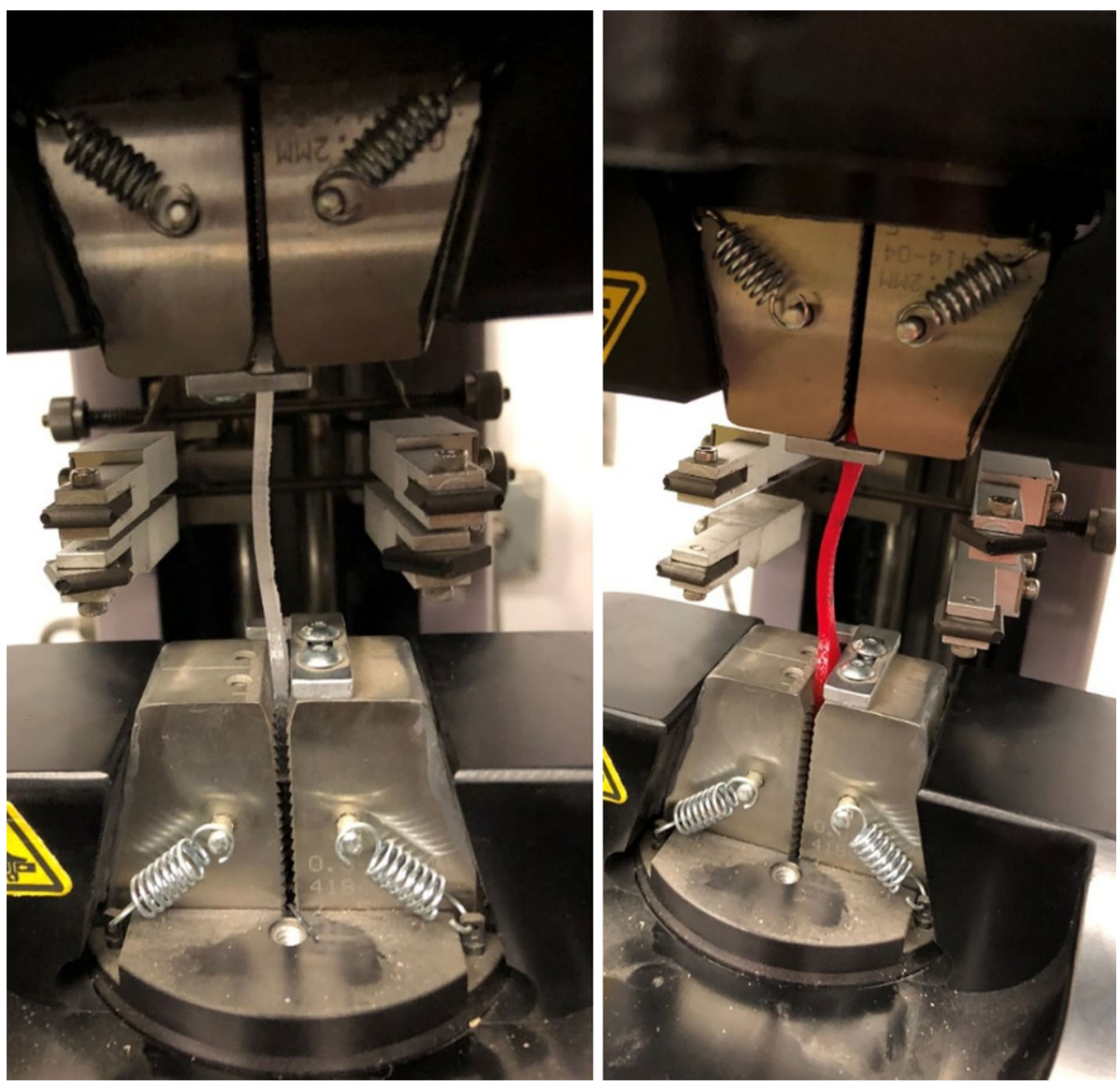

Table 2 Yield Strength values for the materials tested in this study

\begin{tabular}{lccccccc}
\hline & \multicolumn{3}{c}{ PLA } & & \multicolumn{3}{c}{ PETG } \\
\cline { 2 - 5 } \cline { 7 - 8 } & $\begin{array}{c}\text { Mean YS } \\
(\mathrm{MPa})\end{array}$ & $\sigma$ & $\begin{array}{c}\text { Sample } \\
\text { size, } n\end{array}$ & & $\begin{array}{c}\text { Mean YS } \\
(\mathrm{MPa})\end{array}$ & $\sigma$ & $\begin{array}{c}\text { Sample } \\
\text { size, } n\end{array}$ \\
\hline Baseline & 63.98 & 1.22 & 4 & & 42.91 & 1.20 & 4 \\
CV & 58.38 & 0.65 & 3 & & 41.61 & 0.75 & 4 \\
Coke & 53.91 & 1.11 & 3 & & 41.12 & 0.34 & 3 \\
DW & 55.08 & 2.23 & 3 & & 39.15 & 0.86 & 3 \\
ETOH & 49.28 & 1.33 & 4 & & 42.96 & 0.90 & 3 \\
WV & 57.21 & 3.70 & 3 & & 40.05 & 0.26 & 3 \\
\hline
\end{tabular}

Difference (HSD) test with an $\alpha=0.05$ (JMP $^{\circledR}$ 11.2.1 Software, SAS Institute, Inc., Cary, NC, USA) was applied to the tensile data sets for each material type and revealed that all liquid media had statistically significant effect on the yield strength of PLA specimens exposed for a seven day duration (Fig. 6). Conversely, applying the HSD test to the PETG data revealed that exposure to ETOH and DW led to a significant decrease in YS as compared to baseline specimens, while the other liquids did not. The media that had the most effect on the YS values of exposed PLA specimens was ETOH, which produced YS values of
$49.28 \pm 1.33 \mathrm{MPa}$ as compared to baseline values of $63.98 \pm 1.22 \mathrm{MPa}$, a decrease of $23 \pm 0.76 \%$. In the case of PETG, the specimens exposed to DW led to the lowest YS values of $39.15 \pm 0.86 \mathrm{MPa}$ compared to $42.91 \pm 1.20 \mathrm{MPa}$, a difference of $8.75 \pm 0.31 \%$. Exposure of ABS specimens manufactured by the FFF process and exposed to water have been shown elsewhere to exhibit decrease the tensile properties due to the absorption of moisture [25], and it was expected that similar behavior would be observed here.

Representative DMA curves of the baseline specimens are seen in Fig. 7. In the case of PLA, analysis revealed the glassy onset, based on the inflection point of the storage modulus curve, to occur at $54.61{ }^{\circ} \mathrm{C}$, while the max $\tan \delta$ occurred at $69.36^{\circ} \mathrm{C}$. In the case of PETG, glassy behavior began at $74.4^{\circ} \mathrm{C}$, while the $\max \tan \delta$ was observed at $88.74{ }^{\circ} \mathrm{C}$. These measured values correspond with the $T_{\mathrm{g}}$ range for both PLA and PETG found in the literature $[27,28]$. The DMA data for all conditions and materials used in this study are tabulated in Table 3 for PLA and Table 4 for PETG.

In the case of PLA, the storage modulus recorded at the onset of glassy behavior was decreased by an order of magnitude or more as compared to the baseline value of $1.24 \times 10^{10} \mathrm{~Pa}$. The lowest storage modulus value 
PLA

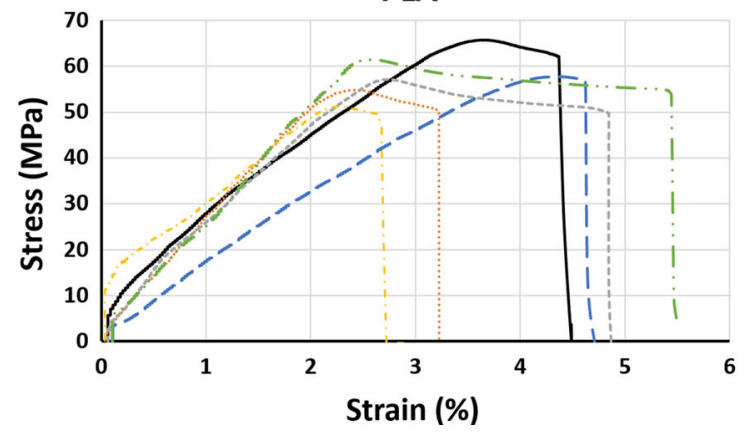

PETG

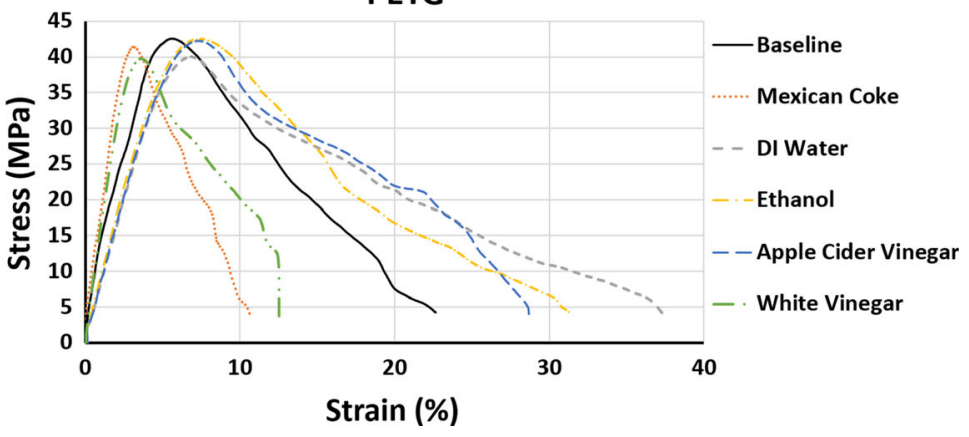

Fig. 5 Representative stress-strain curves for PLA and PETG exposed to various liquid media

Fig. 6 Tukey-Kramer HSD analysis of (a) PETG tensile test results and (b) PLA tensile test results

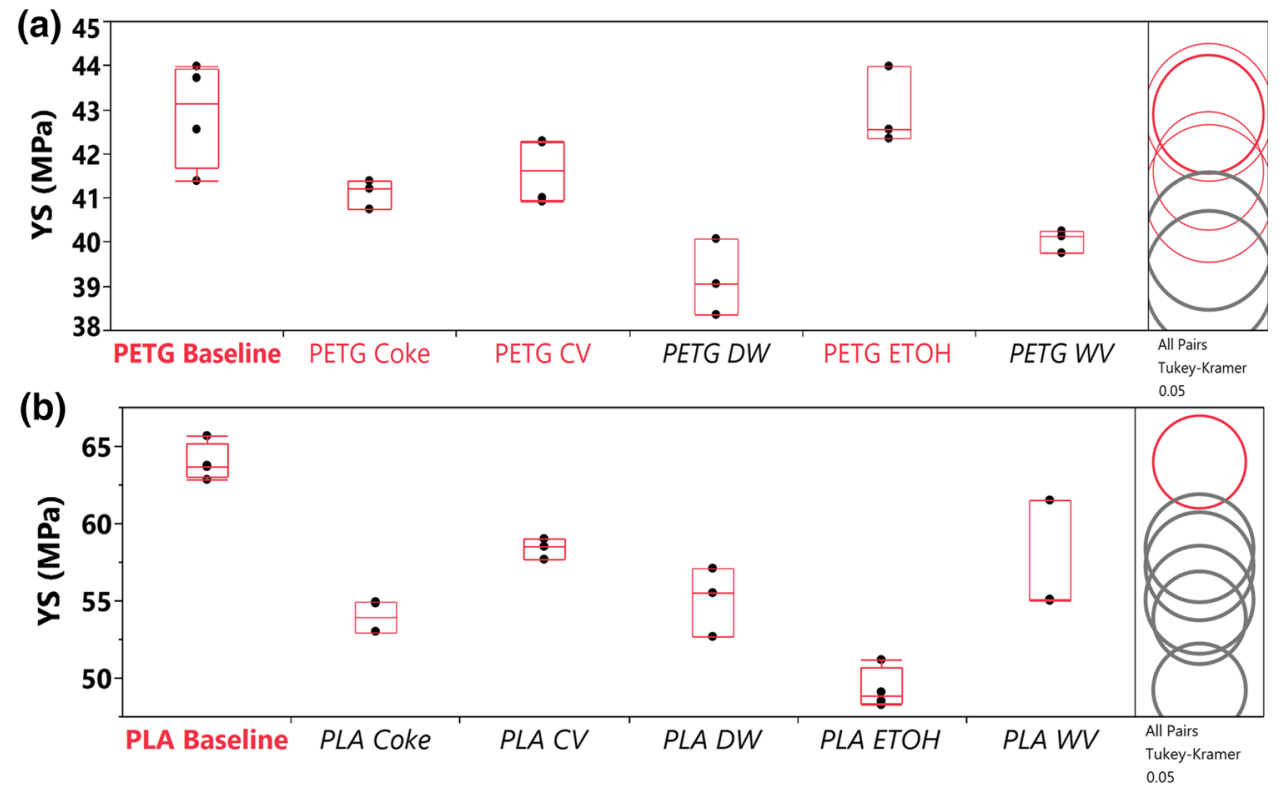

Table 3 Tabulated DMA data for the PLA specimens examined in this study

\begin{tabular}{lccccc}
\hline & \multicolumn{4}{c}{ DMA data for PLA* } \\
\cline { 2 - 3 } & \multicolumn{2}{c}{ Storage modulus } & & \multicolumn{2}{c}{ Loss tangent } \\
\cline { 2 - 3 } \cline { 5 - 6 } Condition & $\begin{array}{c}\text { Glassy onset } \\
(\mathrm{Pa})\end{array}$ & $\begin{array}{c}\text { Temperature } \\
\left({ }^{\circ} \mathrm{C}\right)\end{array}$ & $\begin{array}{c}\text { Max Tan } \\
\delta\end{array}$ & $\begin{array}{c}\text { Temperature } \\
\left({ }^{\circ} \mathrm{C}\right)\end{array}$ \\
\hline Baseline & $1.24 \times 10^{10}$ & 54 & & 1.41 & 69.3 \\
CV & $1.01 \times 10^{9}$ & 51 & & 1.35 & 65 \\
Coke & $1.00 \times 10^{9}$ & 51 & & 1.39 & 64 \\
DW & $3.03 \times 10^{8}$ & 54 & & 1.65 & 66 \\
ETOH & $6.96 \times 10^{8}$ & 58.3 & & 1.08 & 64.3 \\
WV & $1.07 \times 10^{9}$ & 53 & & 1.42 & 70.7 \\
\hline
\end{tabular}

*Frequency of $1 \mathrm{~Hz}$

observed at glassy onset was the DW specimen with a measured value of $3.08 \times 10^{8} \mathrm{~Pa}$. The temperature of glassy onset was also decreased to $51{ }^{\circ} \mathrm{C}$ as compared to the value of $54{ }^{\circ} \mathrm{C}$ recorded for the baseline specimen. The
Table 4 Tabulated DMA data for the PETG specimens examined in this study

\begin{tabular}{lccccc}
\hline & \multicolumn{4}{c}{ DMA data for PETG* } \\
\cline { 2 - 3 } & \multicolumn{2}{c}{ Storage modulus } & & \multicolumn{2}{c}{ Loss tangent } \\
\cline { 2 - 3 } \cline { 5 - 6 } Condition & $\begin{array}{c}\text { Glassy onset } \\
(\mathrm{Pa})\end{array}$ & $\begin{array}{c}\text { Temperature } \\
\left({ }^{\circ} \mathrm{C}\right)\end{array}$ & $\begin{array}{c}\text { Max Tan } \\
\delta\end{array}$ & $\begin{array}{c}\text { Temperature } \\
\left({ }^{\circ} \mathrm{C}\right)\end{array}$ \\
\hline Baseline & $6.44 \times 10^{8}$ & 74.4 & & 1.22 & 88.7 \\
CV & $7.85 \times 10^{8}$ & 71 & & 1.18 & 85 \\
Coke & $2.72 \times 10^{8}$ & 66.9 & & 1.08 & 84.9 \\
DW & $8.57 \times 10^{8}$ & 71.6 & & 1.2 & 86.5 \\
ETOH & $2.4 \times 10^{8}$ & 74.3 & & 0.95 & 88.6 \\
WV & $3.14 \times 10^{8}$ & 68 & & 1.08 & 86.2 \\
\hline
\end{tabular}

*Frequency of $1 \mathrm{~Hz}$

maximum loss tangent $(\tan \delta)$ value was greater for the specimen exposed to DW-a value of 1.65 as compared to the baseline value of 1.41 -indicating that more energy was dissipated as heat during the test and that the elasticity 
(a)
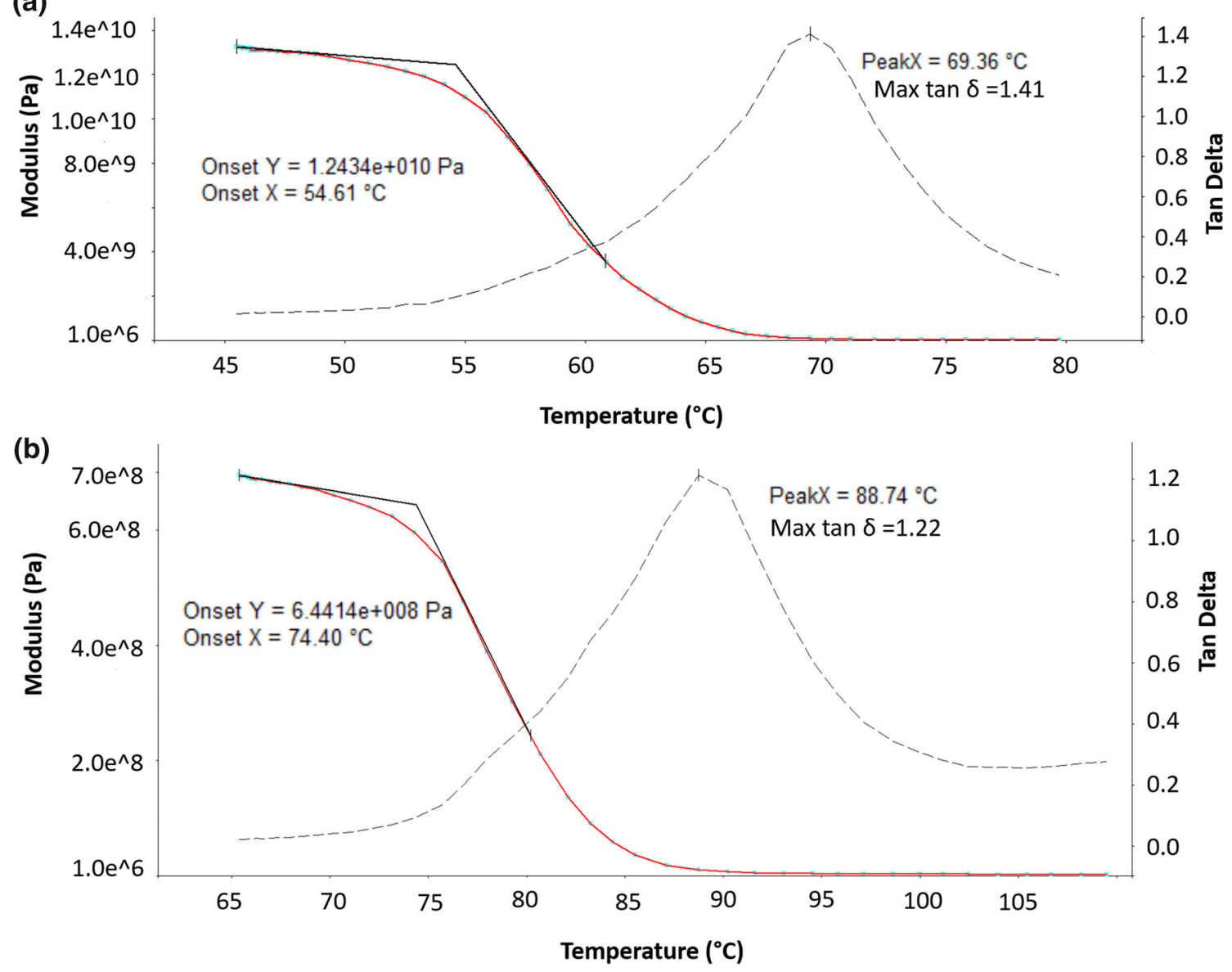

Fig. 7 Baseline DMA curves for (a) PLA and (b) PETG

of the material was decreased due to exposure. The behavior of the DMA specimen exposed to DW is indicative of the hygroscopic nature of PLA, which has been observed in the past by our group based on melt flow index (MFI) evaluations [7, 29] and is also well documented in the literature [30-32].

Exposure to ETOH also resulted in a drop in the storage modulus measured at the glassy onset temperature, but did not lead to an increase of the max $\tan \delta$. Literature indicates that ethanol readily infiltrates porous PLA structures [33] due to surface energy effects and that it also aids in chemical attack of ester chemical bonds [34, 35]. The ability of ETOH to easily permeate the porous FFF-manufactured component and potentially alter the ester bond within the macromolecular chain is most likely the mechanism for the change in rheological properties as compared to the baseline specimen. Though the decrease in storage modulus value was similar to that observed by the hygroscopic behavior of the specimen exposed to DW, the overall effect on the rheology of the material was different as: (1) the temperature of glassy onset was increased to $58.3{ }^{\circ} \mathrm{C}$; and (2) the max $\tan \delta$ decreased to 1.08 compared to 1.41 for the baseline specimen. Exposure to ETOH effectively made the PLA specimen more elastic as compared to the baseline specimen and other exposed specimens.

The storage modulus of a material is similar in nature to the modulus of resilience calculated from the linear elastic region of a stress-strain curve ending at the yield stress point. Considering this analogy, the lowering of storage modulus values for all exposed PLA test components as compared to the baseline specimen is consistent with the lowering of yield strength values. Though the storage modulus value at glassy onset for the PLA specimen exposed to $\mathrm{WV}$ was also decreased, the $\max \tan \delta$ value and temperature were not affected.

In the case of PETG exposed to various liquids, the storage modulus values at glassy onset were not drastically affected. However, the temperature of glassy onset was lowered most greatly for the specimens exposed to Coke and $\mathrm{WV}$, which showed glassy behavior at temperatures of 66.9 and $68{ }^{\circ} \mathrm{C}$, respectively, compared to the baseline value of $74.4{ }^{\circ} \mathrm{C}$. As was the case for PLA, the PETG specimen exposed to ETOH exhibited the lowest $\max \tan \delta$ 

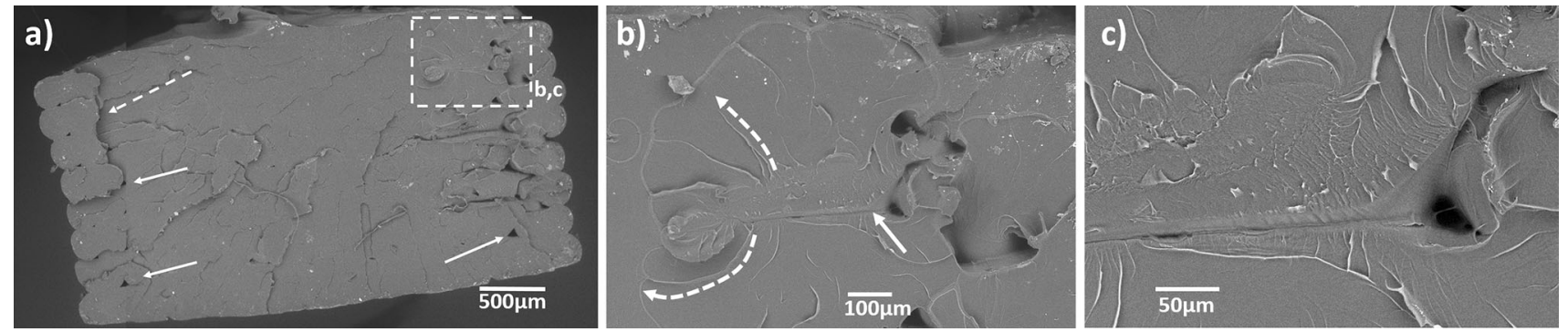

Fig. 8 Scanning electron micrographs of a baseline PLA specimen, where (a) is a low magnification image and (b) and (c) are higher magnification images of the area highlighted by the dashed box in (a)

value of 0.95 compared to the baseline value of 1.22 . Again, like PLA, PETG is a polyester, so the aforementioned possibility of affecting the ester chemical bonds would also be expected to occur. In contrast, unlike observations made with the PLA specimens, exposure to Coke and WV had a noteworthy effect on the max $\tan \delta$ values where both exhibited a value of 1.08 compared to the baseline of 1.22. The driver for this change in $\max \tan \delta$ could be the acidic attack on the polymeric chains as low $\mathrm{pH}$ substances have been shown to lead to polymer degradation by way of chain scission [36, 37]. Chain scission may also be the cause of the temperature drop at $\max \tan \delta$ for the specimen exposed to $\mathrm{CV}$ as this liquid media is also acidic.

As indicated above, the majority of the PLA and PETG specimens failed outside of the gage section. This indicates that there was potentially some defect within each printed test specimen. Scanning electron micrographs (Fig. 8) of the fracture surface taken from a representative PLA baseline specimen reveal characteristics of a brittle failure as there is a low amount of plastic deformation. Also, the micrographs reveal there was poor adhesion between the perimeter raster beads and the crisscross infill print raster beads as indicated by the voids highlighted by solid white arrows in Fig. 8a. The voids indicate that not enough thermal energy was present to allow for polymer diffusion kinetics to increase the neck width between beads and promote polymer chain migration between the individual beads of material [38]. Referring to Fig. 2, there were three perimeter shells used in the printing of the tensile specimens. In other work performed by our group, we avoided the use of perimeter shells to reduce the potential for stress concentrator generation [17, 39]. Here, the interior crisscross raster pattern did not allow enough dwell time for the tool head at the interface between the final perimeter bead and the infill raster beads. The dashed white arrow in Fig. 8a highlights delamination between the perimeter beads and the infill material of the printed specimen. The higher magnification images (Fig. $8 \mathrm{~b}$ and c) indicate strain fields emanating from the vertical raster interface (solid white arrow) where the dashed white lines indicate the craze crack propagation. The higher magnification image (Fig. 8c) allows further observation of the mirror, mist and hackle zones in order progressing away from the print raster interface.

Fractographic analysis of the PETG baseline specimen (Fig. 9a) reveals that, as compared to the PLA specimen, more plastic deformation occurred prior to final rupture as indicated by the presence of necking. This is to be expected as the glycol modification of PET effectively acts as a plasticizer and increases toughness as compared to PET alone. Overall, the majority of the PETG specimens failed in a manner that yielded a morphology similar to a "cup and cone" shape observed on ductile metal cylindrical tensile test specimens. The large cusp in the interior of the specimen observed in Fig. 9a is analogous to the "cup" side. Again, there was delamination between the perimeter and internal print rasters (indicated by the solid white arrow in Fig. 9a). The higher magnification image in Fig. 9b indicates that craze cracking did occur, but there was more plastic deformation associated as the ridges are more pronounced as compared to the fracture surface observed on the PLA specimen. Mixed mode failure indicating craze cracking and delamination between the print rasters is observed in Fig. 9c.

Electron micrographs of the PLA specimen exposed to CV (Fig. 10) again reveal a brittle fracture mode; however, secondary cracking (highlighted by the white arrows in Fig. 10b) indicates that specimen was weaker as compared to the baseline specimen. Though there are print-induced voids observed (solid white arrow in Fig. 10a), the difference in fracture morphology indicates that exposure to the $\mathrm{CV}$ altered the material at a molecular level. The higher magnification micrograph (Fig. 10c) reveals the formation of fibrils of varying size. The observations made pertaining to the fracture morphology are consistent with the results of the DMA testing.

As was the case for the baseline PETG specimen, the sample exposed to CV exhibited a high level of plastic deformation prior to rupture. In this case, the observed specimen would be analogous to the cone side following the reference to "cup and cone" morphology. The most 

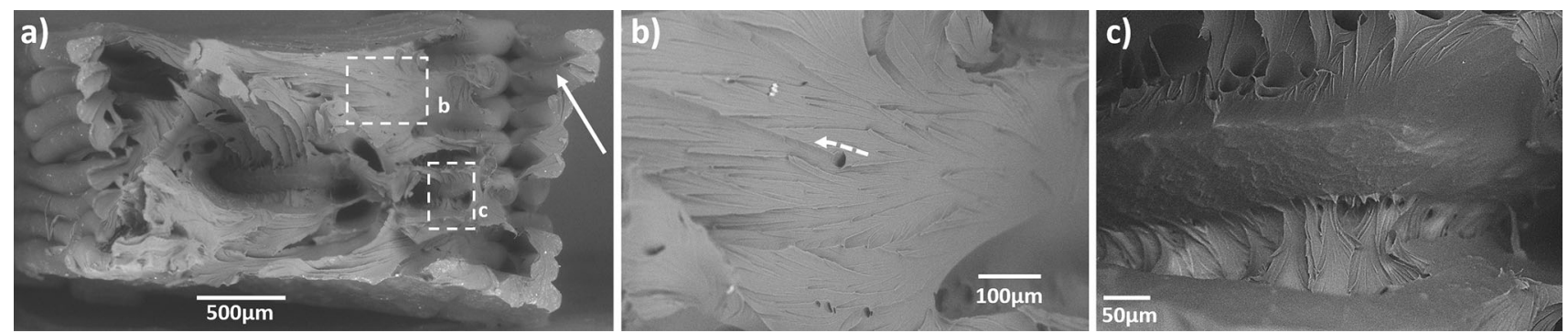

Fig. 9 Scanning electron micrographs of a baseline PETG specimen, where (a) is a low magnification image and (b) and (c) are higher magnification images of the area highlighted by the dashed box in (a)
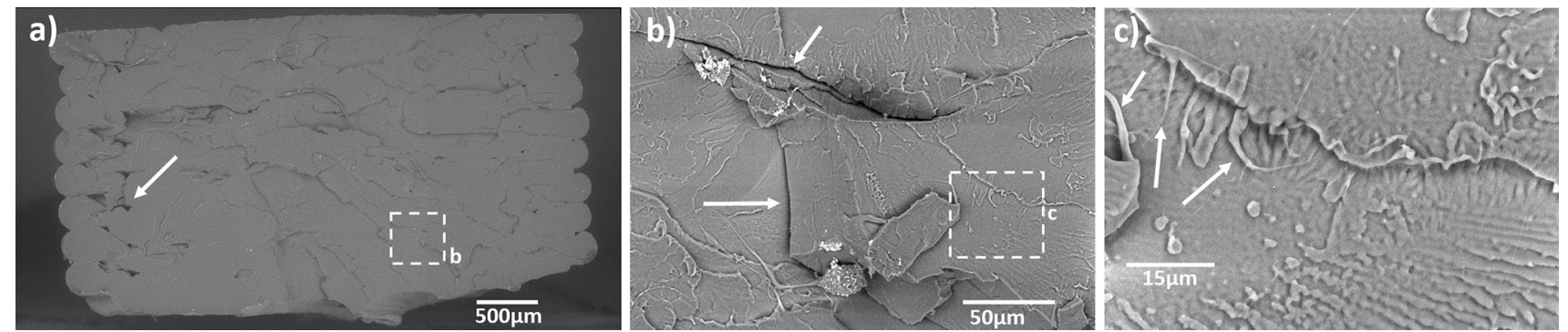

Fig. 10 Scanning electron micrographs of (a) PLA specimen that was exposed to apple cider vinegar. Note the presence of secondary cracking in (b) as well as the presence of large fibrils in (c)
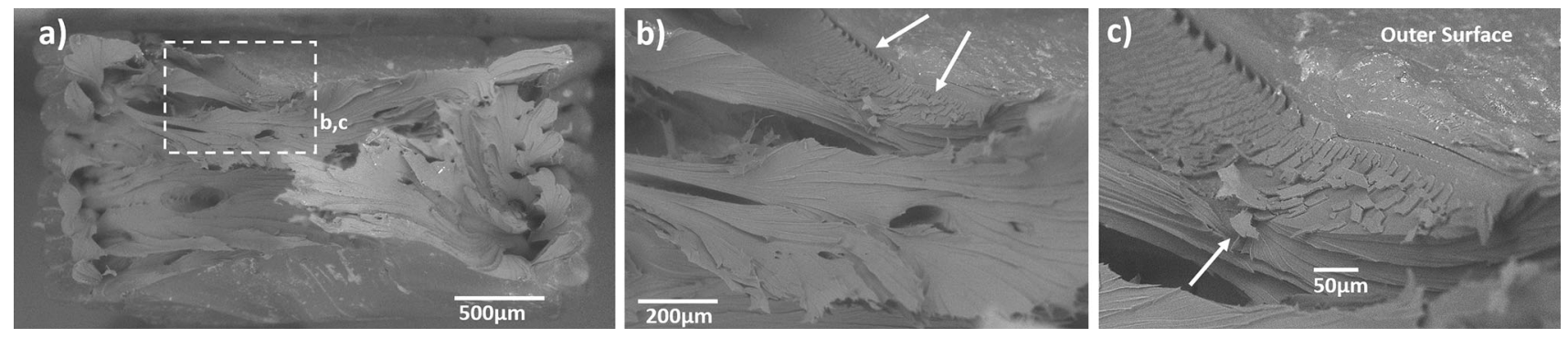

Fig. 11 Scanning electron micrographs of (a) PETG specimen that was exposed to apple cider vinegar for seven days. The most notable feature is the presence of mud cracking highlighted by white arrows in (b) and (c)

notable observation on this specimen was the presence of mud cracking as indicated by the solid white arrows in Fig. 11b and c. Mud cracking is indicative of molecular damage associated with hydrolysis of the polymer chains and is more serious than hygroscopicity as it is irreversible [40, 41]. As indicated by the electron micrograph presented in Fig. 11c, the mud cracking occurred near the outer surface of the test specimen meaning that the liquid media penetrated between the print rasters and degraded the material in varying levels of severity.

Consistent with the other PLA specimens observed in this study, the specimen exposed to Coke (Fig. 12) also presented a fracture morphology dominated by craze cracking and smooth planes indicative of brittle failure. A notable feature on this fracture surface was the void in the middle of the specimen. The higher magnification micrograph in Fig. 12b indicates that there was delamination between the print rasters as highlighted by the white arrows. Delamination parallel to the build direction occurred between the perimeter rasters highlighted by the white arrow in Fig. 12c. The distinct features observed on this specimen were more likely caused by variability within the printing process as opposed to exposure to the liquid media.

The PETG specimen exposed to Coke (Fig. 13) exhibited a high degree of plastic deformation and delamination between the print rasters as highlighted by the white arrow in Fig. 13a. Shear bands can be seen on the outer surface of the specimen as indicated by dashed arrows (Fig. 13a). The presence of a shear lip (Fig. 13b) indicates that, at that area, crack propagation radiated from the delamination point outward. Figure 13c shows another case of delamination between the print rasters.

Electron microanalysis of the PLA specimen exposed to DW revealed the presence of a cleavage stop (highlighted 

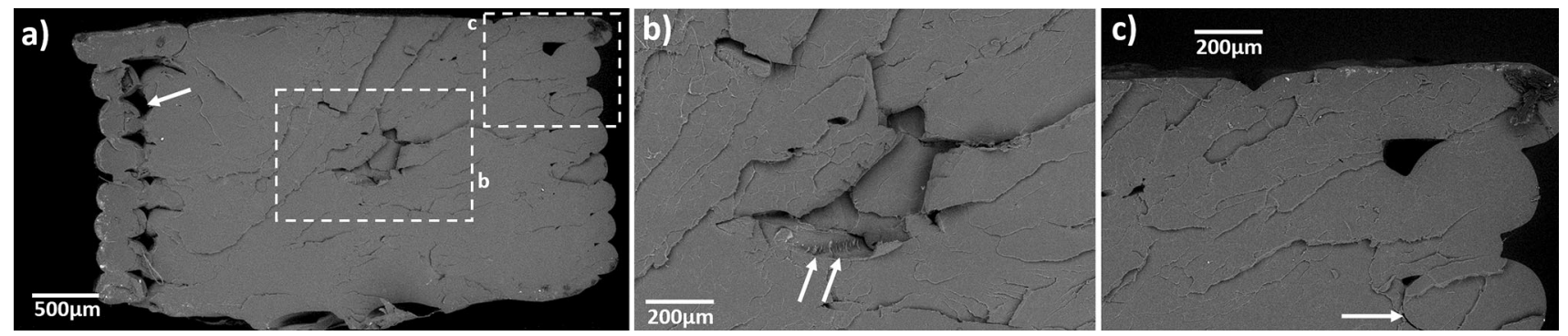

Fig. 12 Scanning electron micrographs of a PLA specimen exposed to Mexican Coca-cola for a period of seven days, where (a) is a low magnification image and (b) and (c) are higher magnification images of the areas highlighted by the dashed boxes in (a)
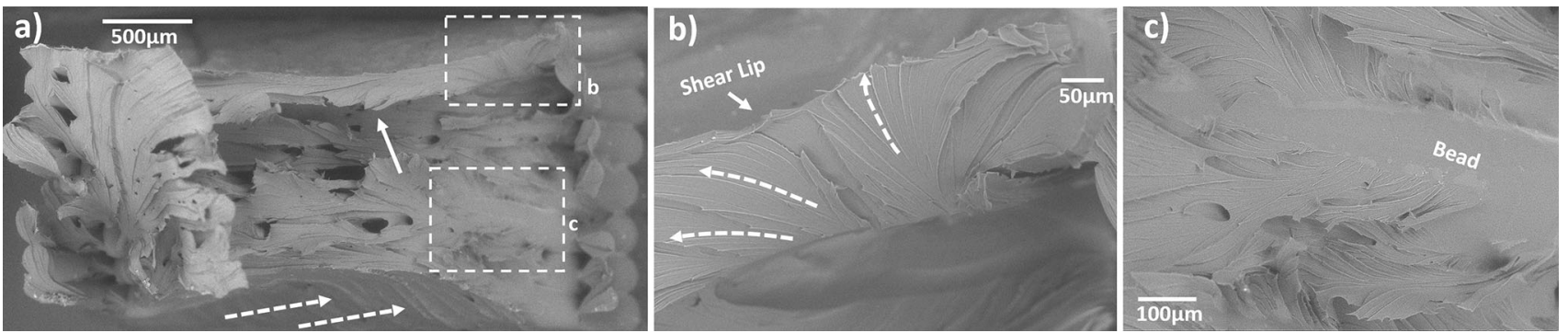

Fig. 13 Scanning electron micrographs of a PETG specimen exposed to Mexican Coca-cola for a period of seven days where a large can be seen in (a). The higher magnification in (b) indicates localized crack propagation terminating at a shear lip and (c) indicates delamination between print beads

Fig. 14 Scanning electron micrographs of (a) PLA specimen exposed to distilled water for a period of seven days where a cleavage stop is indicated by the white arrows in (a). The higher magnification in (b) exhibits fibrils and morphology consistent with craze cracking
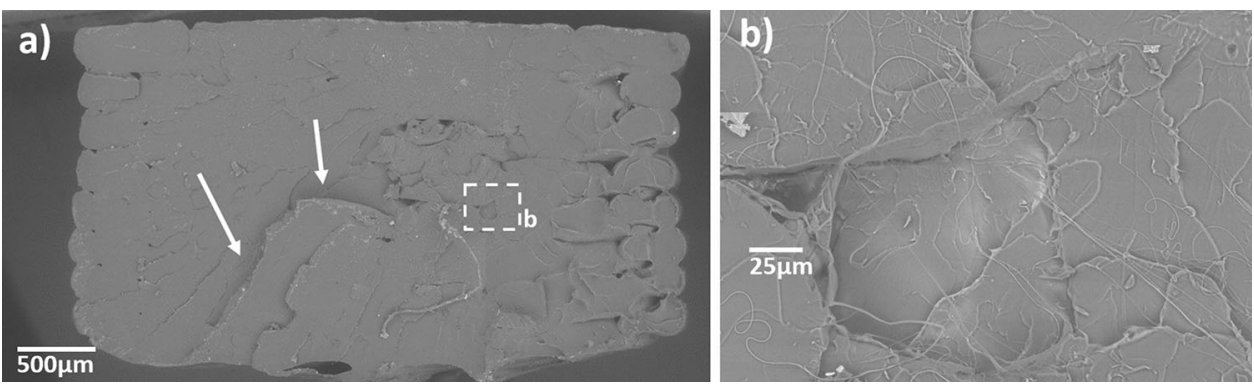

by solid white arrows in Fig. 14a) near the center of the specimen [42]. The higher magnification micrograph seen in Fig. 14b reveals that fibrils manifested during the tensile testing of the specimen. The presence of fibrils is consistent with observations made during DMA testing, which highlighted the hygroscopic nature of PLA.

As was the case with the other PETG specimens evaluated in this work, the specimen exposed to DW (Fig. 15) exhibited a high degree of plastic deformation. Again, following suit with the "cup and cone" tensile test model, the specimen observed in this case corresponds with the cone. The higher magnification micrograph seen in Fig. 15b illustrates another instance of bead delamination occurring during the tensile test.

Observation of the fracture surface from a PLA specimen that was exposed to ETOH for a period of seven days indicates that the mode of failure was brittle in nature as there is a low amount of plastic deformation present. The presence of stress fields is evident on the fracture plane as highlighted by the white arrows in Fig. 16a. The higher magnification electron micrograph (Fig. 16b) indicates that the field emanated from the inner raster interface between vertical build layers as was observed previously.

In the case of the PETG specimen exposed to ETOH, delamination between print rasters is a dominant feature (Fig. 17b and c). Along with the large amount of printinduced voids (highlighted by white arrows in Fig. 17a) on this and other PETG specimens, the presence of delamination is an indicator that the print temperature was too low and the print speed too high to allow for adequate diffusion to occur in order to form a robust interface between print layers for all the PETG specimens evaluated here.

The PLA specimen exposed to WV exhibited delamination of the interior print rasters in a direction parallel to the applied stress (indicated by white arrows in Fig. 18a). Another notable feature observed on this specimen is the 

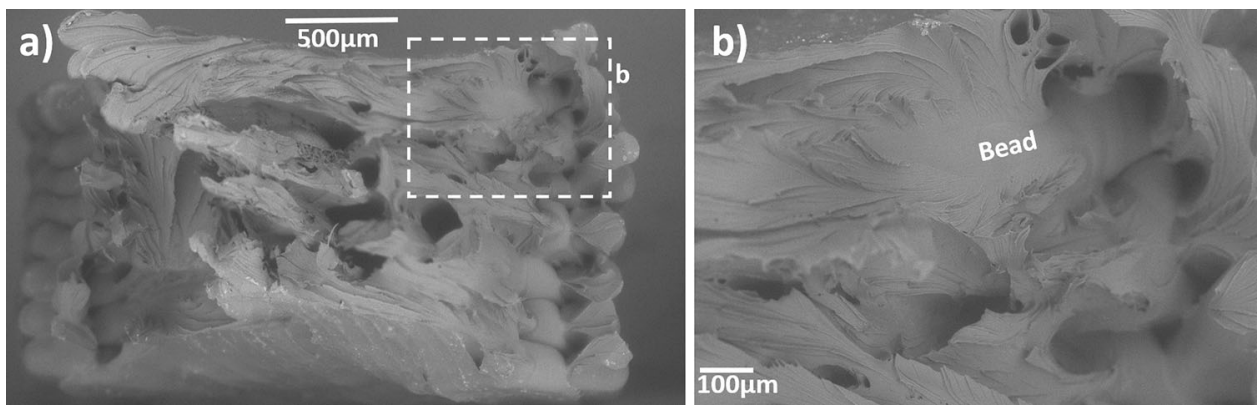

Fig. 15 Scanning electron micrographs of a PETG specimen exposed to distilled water for a period of seven days where a large amount of plastic deformation and print-induced voids can be seen in (a). The higher magnification in (b) indicates localized crack propagation emanating from a print raster interface that delaminated
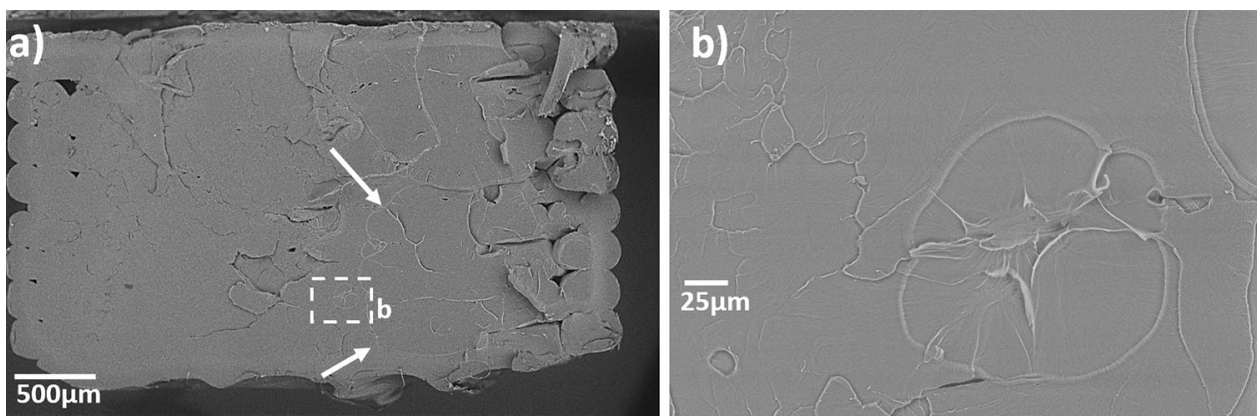

Fig. 16 Scanning electron micrographs of a PLA specimen exposed to 200 proof ethanol for a period of seven days where a brittle fracture mode morphology is present on the fracture surface along with bisected stress fields as indicated by white arrows in (a). A higher magnification image of a stress field can be seen in (b)
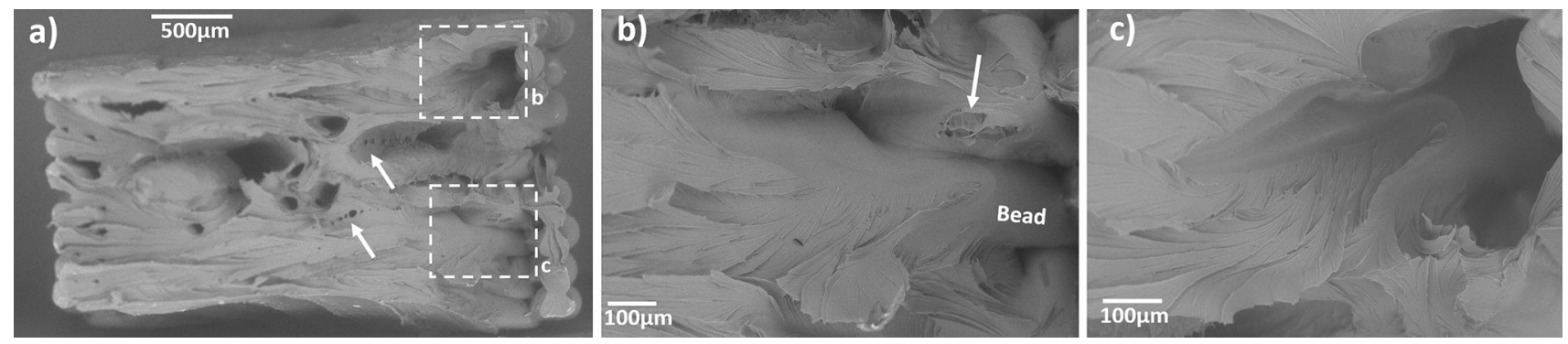

Fig. 17 Scanning electron micrographs of a PETG specimen exposed to 200 proof ethanol for a period of seven days where many voids are present as indicated by white arrows in (a). The higher magnification in (b) and (c) indicate delamination between the print beads

presence of fibrils (Fig. 18b) in the center of the specimen, indicating that crack propagation occurred more slowly in this region and that molecular damage occurred as a result of exposure to the liquid media. Stress fields were observed to emanate from the vertical (parallel to build direction) print raster interfaces near the edge of the specimen (Fig. 18c). Here, stress fields that emanated from subsequent print rasters intersected one another. Delamination between the perimeter raster beads characterized by secondary cracking between the vertical print raster (highlighted by white arrow in Fig. 18c) indicates, again, that not enough thermal energy was present at the edge of the specimen to promote polymer diffusion.
Analysis via electron microscopy of the PETG specimen exposed to $\mathrm{WV}$ was also dominated by delamination between the print rasters (Fig. 19). The solid arrow in Fig. 19a indicates crack propagation originating at the surface of the specimen, while the dashed arrow indicates crack initiation within the specimen. Bead delamination is again indicated in Fig. 19b, while deformation below the fracture plane was observed within the void in Fig. 19c.

While there was a discernable effect due to the exposure of mechanical test specimens to liquid media, the contribution to failure modes by defects induced by the additive manufacturing process itself were extremely apparent in the fractographic analysis. Additive manufacturing has 


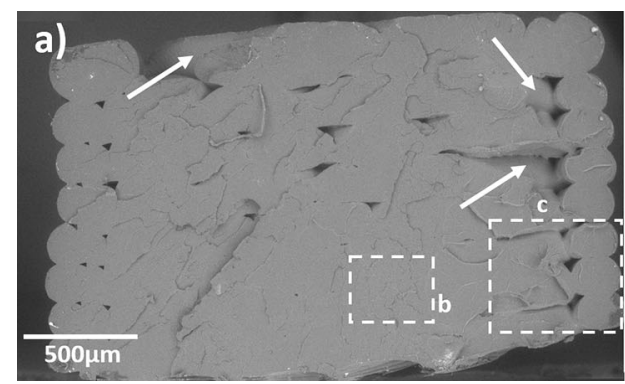

Fig. 18 Scanning electron micrographs of (a) PLA specimen exposed to distilled white vinegar for a period of seven days where craze cracking and print-induced voids are the predominant feature observed on the fracture surface. The higher magnification in (b)
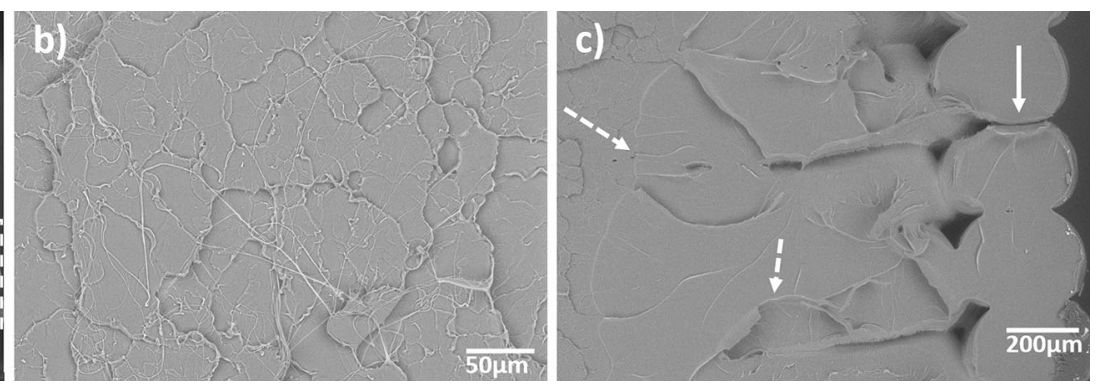

indicates localized formation of fibrils. The predominant features seen in the higher magnification in (c) are stress fields emanating from the print raster interface and delamination of the print beads
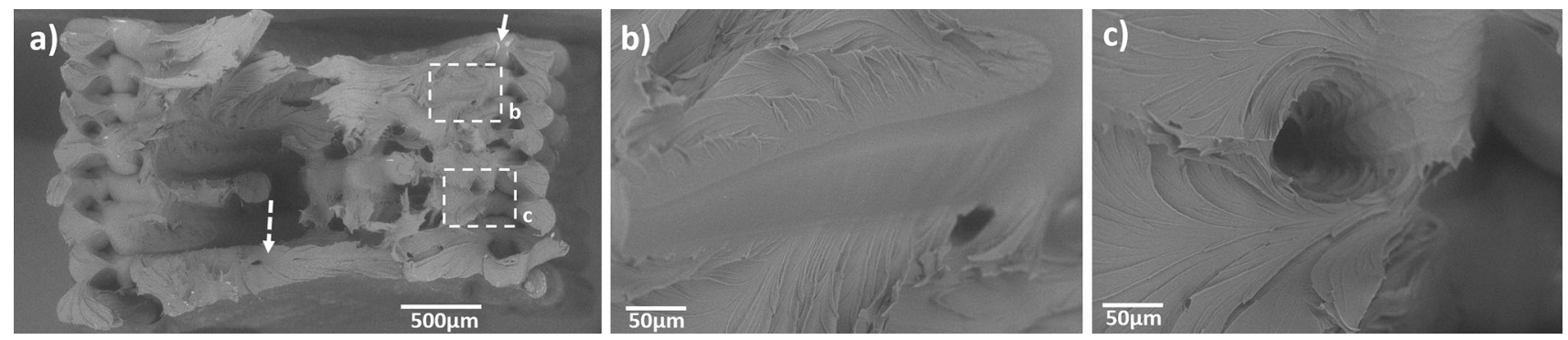

Fig. 19 Scanning electron micrographs of a PETG specimen exposed to distilled white vinegar for a duration of seven days, where (a) is a low magnification image and (b) and (c) are higher magnification images of the areas highlighted by the dashed boxes in (a)

been steadily increasing in use for over twenty years, yet there remain no AM-specific standards for material testing. Other research efforts performed by our group have highlighted the need for unique material testing standards for AM processes [17, 19, 43], and the work presented here also serves as an example of the need for specific procedures for test coupon manufacturing, in this case for the monitoring of the effect of environmental conditions. At the very least, a printing pattern sans the presence of stress concentrating features should be employed.

\section{Conclusions}

Submerging additively manufactured tensile specimens composed of two polyesters-polylactic acid (PLA) and glycol-modified polyethylene terephthalate (PETG)—had an effect on the mechanical properties of both materials. The changes in physical properties were most notable when adjudicating the results of dynamic mechanical analysis where exposure to ethanol had the greatest effect on maximum loss tangent most likely due to the degradation of ester bonds. Though we experienced problems with mechanical testing, the results were robust enough to allow for scrutiny of yield strength results well as the analysis of fracture surfaces via electron microscopy. Statistical analysis of the yield strength values indicated that all liquid media had a statistically significant effect on the exposed PLA specimens, while, in the case of PETG, white vinegar and distilled water had the most profound effect as compared to non-exposed baseline specimens.

Analysis of the fracture surfaces revealed that defects introduced by the printing process itself are the significant contributors to the failure of the specimens. Key features such as stress fields emanating from print raster interfaces and delamination of the individual printed beads of material as well as the presence of voids due to either print raster pattern or inadequate machine parameters are all nuances of additively manufactured components that add a level of complexity to failure analysis of 3D-printed components. Despite the presence of print-induced defects, features caused by exposure to liquid media were also apparent such as the presence of mud cracking caused by molecular damage due to the exposing of PETG to apple cider vinegar.

As thermoplastic-based FFF platforms are expected to be used to manufacture components ranging in complexity from that of simple brackets and coffee cups to parts intended for aerospace applications, an understanding of the resilience of a printed component to the environment it is deployed within must be made. In order to gain such an understanding, standardized procedures for the evaluation of the effect of environmental effects must be established. 
Acknowledgments The work presented here was the result of the effort of the students enrolled in the Fall, 2018 section of MME 4310/ 5390 Polymer Engineering. We are grateful for the resources made available to us by the Department of Metallurgical, Materials and Biomedical Engineering (MMBME) at The University of Texas at El Paso (UTEP). We express our appreciation and gratitude to the MMBME Department Chair, Dr. Stella A. Quiñones for her support. We also thank the Research Assistants in the Polymer Extrusion Lab for their significant contribution to this work.

\section{References}

1. B. Stephens, P. Azimi, Z. El Orch, T. Ramos, Ultrafine particle emissions from desktop 3D printers. Atmos. Environ. 79, 334339 (2013). https://doi.org/10.1016/j.atmosenv.2013.06.050

2. P. Azimi, D. Zhao, C. Pouzet, N.E. Crain, B. Stephens, Emissions of ultrafine particles and volatile organic compounds from commercially available desktop three-dimensional printers with multiple filaments. Environ. Sci. Technol. (2016). https://doi.org/ 10.1021/acs.est.5b04983

3. Flynt J. 3D Printer Filament Guide - 23 + Types of Materials. 3D Insid (2018). https://3dinsider.com/3d-printer-filaments/. Accessed 18 Dec 2018

4. R.B. Dupaix, M.C. Boyce, Finite strain behavior of poly(ethylene terephthalate) (PET) and poly(ethylene terephthalate)-glycol (PETG). Polymer 46, 4827-4838 (2005). https://doi.org/10.1016/ j.polymer.2005.03.083

5. B. Wittbrodt, J.M. Pearce, The effects of PLA color on material properties of 3-D printed components. Addit Manuf 8, 110-116 (2015). https://doi.org/10.1016/j.addma.2015.09.006

6. L. Yu, H. Liu, F. Xie, L. Chen, X. Li, Effect of annealing and orientation on microstructures and mechanical properties of polylactic acid. Polym. Eng. Sci. 48, 634-641 (2008). https://doi. org/10.1002/pen.20970

7. C.R. Rocha Gutierrez, Improving the engineering properties of PLA for $3 D$ printing and beyond (The University of Texas at El Paso, Ph.D, 2016)

8. T. Ke, X. Sun, Melting behavior and crystallization kinetics of starch and poly(lactic acid) composites. J. Appl. Polym. Sci. 89, 1203-1210 (2003). https://doi.org/10.1002/app.12162

9. K.-L.G. Ho, A.L. Pometto, A. Gadea-Rivas, J.A. Briceño, A. Rojas, Degradation of polylactic acid (PLA) plastic in costa rican soil and Iowa State University compost rows. J. Environ. Polym. Degrad. 7, 173-177 (1999). https://doi.org/10.1023/a: 1022874530586

10. S. Farah, D.G. Anderson, R. Langer, Physical and mechanical properties of PLA, and their functions in widespread applications-a comprehensive review. PLA Biodegrad Polym. 107, 367-392 (2016). https://doi.org/10.1016/j.addr.2016.06.012

11. J.G.B. Derraik, The pollution of the marine environment by plastic debris: a review. Mar. Pollut. Bull. 44, 842-852 (2002). https://doi.org/10.1016/S0025-326X(02)00220-5

12. S.L. Dautel, Transoceanic Trash: International and United States Strategies for the Great Pacific Garbage Patch Farming and Food: How We Grow What We Eat: Comment. Gold Gate Univ. Environ. Law J. 3, 181-208 (2009)

13. J. Kaiser, The dirt on ocean garbage patches. Science 328, 1506 (2010). https://doi.org/10.1126/science.328.5985.1506

14. H. Hirai, H. Takada, Y. Ogata, R. Yamashita, K. Mizukawa, M. Saha et al., Organic micropollutants in marine plastics debris from the open ocean and remote and urban beaches. Mar. Pollut. Bull. 62, 1683-1692 (2011). https://doi.org/10.1016/j.marpolbul. 2011.06.004
15. K.J. McDermid, T.L. McMullen, Quantitative analysis of smallplastic debris on beaches in the Hawaiian archipelago. Mar. Pollut. Bull. 48, 790-794 (2004). https://doi.org/10.1016/j. marpolbul.2003.10.017

16. D. Hosler, S.L. Burkett, M.J. Tarkanian, Prehistoric Polymers: Rubber Processing in Ancient Mesoamerica. Science 284, 19881991 (1999). https://doi.org/10.1126/science.284.5422.1988

17. A.R. Torrado, D.A. Roberson, Failure analysis and anisotropy evaluation of 3D-printed tensile test specimens of different geometries and print raster patterns. J. Fail. Anal. Prev. 16, 154164 (2016). https://doi.org/10.1007/s11668-016-0067-4

18. A.R. Torrado, C.M. Shemelya, J.D. English, Y. Lin, R.B. Wicker, D.A. Roberson, Characterizing the effect of additives to ABS on the mechanical property anisotropy of specimens fabricated by material extrusion 3D printing. Addit. Manuf. 6, 16-29 (2015). https://doi.org/10.1016/j.addma.2015.02.001

19. D.A. Roberson, A.R. Torrado Perez, C.M. Shemelya, A. Rivera, E. MacDonald, R.B. Wicker, Comparison of stress concentrator fabrication for 3D printed polymeric izod impact test specimens. Addit. Manuf. 7, 1-11 (2015). https://doi.org/10.1016/j.addma. 2015.05.002

20. A. Bellini, S. Güçeri, Mechanical characterization of parts fabricated using fused deposition modeling. Rapid. Prototyp J. 9, 252-264 (2003). https://doi.org/10.1108/13552540310489631

21. A.R.T. Perez, D.A. Roberson, R.B. Wicker, Fracture surface analysis of 3D-printed tensile specimens of novel ABS-based materials. J. Fail. Anal. Prev. 14, 343-353 (2014). https://doi.org/ 10.1007/s11668-014-9803-9

22. S.-H. Ahn, M. Montero, D. Odell, S. Roundy, P.K. Wright, Anisotropic material properties of fused deposition modeling ABS. Rapid Prototyp J 8, 248-257 (2002). https://doi.org/10. 1108/13552540210441166

23. O.S. Es-Said, J. Foyos, R. Noorani, M. Mendelson, R. Marloth, B.A. Pregger, Effect of layer orientation on mechanical properties of rapid prototyped samples. Mater. Manuf. Process. 15, 107-122 (2000). https://doi.org/10.1080/10426910008912976

24. Torrado Perez AR. Defeating anisotropy in material extrusion 3D printing via materials development, Ph.D. thesis The University of Texas at El Paso, 2015

25. E. Kim, Y.-J. Shin, S.-H. Ahn, The effects of moisture and temperature on the mechanical properties of additive manufacturing components: fused deposition modeling. Rapid Prototyp J. 22, 887-894 (2016). https://doi.org/10.1108/RPJ-08-2015-0095

26. 14:00-17:00. ISO 527-1:2012. ISO n.d. http://www.iso.org/cms/ render/live/en/sites/isoorg/contents/data/standard/05/60/56045. html. Accessed 24 Dec 2018

27. J.D. Yoon, S.W. Cha, Change of glass transition temperature of polymers containing gas. Polym Test 20, 287-293 (2001). https:// doi.org/10.1016/S0142-9418(00)00034-9

28. V.S.G. Silverajah, N.A. Ibrahim, N. Zainuddin, W.M.Z.W. Yunus, H.A. Hassan, Mechanical, Thermal and Morphological Properties of Poly(lactic acid)/Epoxidized Palm Olein Blend. Molecules 17, 11729-11747 (2012). https://doi.org/10.3390/ molecules 171011729

29. Siqueiros JG, Roberson DA. In situ wire drawing of phosphate glass in polymer matrices for material extrusion $3 \mathrm{D}$ printing. Int. J. Polym. Sci. (2017)

30. E. Vey, C. Roger, L. Meehan, J. Booth, M. Claybourn, A.F. Miller et al., Degradation mechanism of poly(lactic-co-glycolic) acid block copolymer cast films in phosphate buffer solution. Polym. Degrad. Stab. 93, 1869-1876 (2008). https://doi.org/10. 1016/j.polymdegradstab.2008.07.018

31. J.C. Middleton, A.J. Tipton, Synthetic biodegradable polymers as orthopedic devices. Biomaterials 21, 2335-2346 (2000). https:// doi.org/10.1016/S0142-9612(00)00101-0 
32. H. Abdillahi, E. Chabrat, A. Rouilly, L. Rigal, Influence of citric acid on thermoplastic wheat flour/poly(lactic acid) blends. II. Barrier properties and water vapor sorption isotherms. Ind. Crops Prod. 50, 104-111 (2013). https://doi.org/10.1016/j.indcrop.2013. 06.028

33. A.G. Mikos, M.D. Lyman, L.E. Freed, R. Langer, Wetting of poly(l-lactic acid) and poly(dl-lactic-co-glycolic acid) foams for tissue culture. Biomaterials 15, 55-58 (1994). https://doi.org/10. 1016/0142-9612(94)90197-X

34. C.M.O. Müller, A.T.N. Pires, F. Yamashita, Characterization of thermoplastic starch/poly(lactic acid) blends obtained by extrusion and thermopressing. J. Braz. Chem. Soc. 23, 426-434 (2012). https://doi.org/10.1590/S0103-50532012000300008

35. J. Yang, Y. Wan, C. Tu, Q. Cai, J. Bei, S. Wang, Enhancing the cell affinity of macroporous poly(L-lactide) cell scaffold by a convenient surface modification method. Polym. Int. 52, 18921899 (2003). https://doi.org/10.1002/pi.1272

36. B. Belloncle, C. Bunel, L. Menu-Bouaouiche, O. Lesouhaitier, F. Burel, Study of the degradation of poly(ethyl glyoxylate): biodegradation, toxicity and ecotoxicity assays. J. Polym. Environ. 20, 726-731 (2012). https://doi.org/10.1007/s10924-0120429-2

37. A. Göpferich, Mechanisms of polymer degradation and erosion. Biomaterials 17, 103-114 (1996). https://doi.org/10.1016/01429612(96)85755-3

38. S.A. Gold, R. Strong, B.N. Turner, A review of melt extrusion additive manufacturing processes: I. Process design and modeling. Rapid Prototyp J. 20, 192-204 (2014). https://doi.org/ 10.1108/rpj-01-2013-0012

39. F.A. Chávez, J.G. Siqueiros, I.A. Carrete, I.L. Delgado, G.W. Ritter, D.A. Roberson, Characterisation of phases and deformation temperature for additively manufactured shape memory polymer components fabricated from rubberised acrylonitrile butadiene styrene. Virtual Phys. Prototyp. 0, 1-15 (2018). https:// doi.org/10.1080/17452759.2018.1550694

40. S. Li, Hydrolytic degradation characteristics of aliphatic polyesters derived from lactic and glycolic acids. J. Biomed. Mater. Res. 48, 342-353 (1999). https://doi.org/10.1002/(SICI)10974636(1999)

41. J. Jansen, Plastic failure through molecular degradation. Plast. Eng. 71, 34-39 (2015). https://doi.org/10.1002/j.1941-9635.2015. tb01285.x

42. Ramirez A. Comparison of Extruder Systems for 3D Printer Filament Fabrication. ETD Collect Univ Tex El Paso 2017:1-83

43. K. Schnittker, E. Arrieta, X. Jimenez, D. Espalin, R.B. Wicker, D.A. Roberson, Integrating digital image correlation in mechanical testing for the materials characterization of big area additive manufacturing feedstock. Addit. Manuf. 2, 1-10 (2018). https:// doi.org/10.1016/j.addma.2018.12.016

Publisher's Note Springer Nature remains neutral with regard to jurisdictional claims in published maps and institutional affiliations. 